\title{
The association between infertility and sexual dysfunction in women with obesity
}

\author{
ALPARSLAN DENIZ ${ }^{1}$ and Muhammed Okuyucu ${ }^{2}$ \\ ${ }^{1}$ Alanya Alaaddin Keykubat University \\ ${ }^{2}$ Ondokuz Mayis University Faculty of Medicine
}

July 17, 2021

\begin{abstract}
Background: In this study, sexual function problems in obese infertile women were investigated. Methods: Meeting the inclusion criteria for the study; Included were 150 women obesity without infertility, 150 women obesity with infertility and 150 women normal weight without infertility. The participants were administered a sociodemographic data form, the Female Sexual Function Index (FSFI), and the Beck Depression Inventory following the measurement of body mass index. Results: FSFI scores were observed to be statistifical significantly lower in the group of obesity with infertility than in the other two groups. FSFI scores were measured as $(19.6 \pm 3.6$ vs $21.0 \pm 3.7$ vs $27.1 \pm 4.3)$ in the group of obesity with infertility, the group of obesity without infertility and the control group, respectively. Conclusion: In our study, sexual dysfunction was found to be statistically significantly higher in women obesity with infertility compared to the control group. Therefore, healthcare professionals in women obesity with infertility; in addition to infertility treatment, sexual health counseling should also be considered.
\end{abstract}

\section{The association between infertility and sexual dysfunction in women with obesity}

\section{ABSTRACT}

Background: In this study, sexual function problems in obese infertile women were investigated.

Methods: Meeting the inclusion criteria for the study; Included were 150 women obesity without infertility, 150 women obesity with infertility and 150 women normal weight without infertility. The participants were administered a sociodemographic data form, the Female Sexual Function Index (FSFI), and the Beck Depression Inventory following the measurement of body mass index.

Results: FSFI scores were observed to be statistifical significantly lower in the group of obesity with infertility than in the other two groups. FSFI scores were measured as $(19.6 \pm 3.6$ vs $21.0 \pm 3.7$ vs $27.1 \pm$ 4.3) in the group of obesity with infertility, the group of obesity without infertility and the control group, respectively.

Conclusion: In our study, sexual dysfunction was found to be statistically significantly higher in women obesity with infertility compared to the control group. Therefore, healthcare professionals in women obesity with infertility; in addition to infertility treatment, sexual health counseling should also be considered.

Keywords: Infertility; Sexual dysfunction; Sexual health; Body mass index; Obesity

\section{What's known}

Psychological problems such as depression and anxiety, changes in sex hormones, and adipokines were reported to have negative impacts on sexual functions. There are also various reports stating that female 
infertility has negative effects on sexual satisfaction and that fertility anxiety may affect sexual functions as an independent factor. Even so there is a limited amount of information concerning the effects of obesity and infertility on female sexual function.

\section{What's new}

It has been found in our study that sexual dysfunction is higher in women with obesity and infertility and that this dysfunction is correlated with BMI. It is therefore important that healthcare professionals adopt a holistic approach that incorporates sexual health consultancy to improve the treatment and quality of life in women with obesity and infertility.

\section{INTRODUCTION}

Obesity is a health problem that has adverse effects on human life worldwide. ${ }^{1}$ It causes serious morbidity in population by particularly increasing metabolic syndrome, as well as hypertension, diabetes, and some types of cancer. ${ }^{2}$ It was reported that, in terms of reproductive health, women with obesity had decreased rates of conception and increased rates of miscarriage. ${ }^{3}$ These problems are thought to be associated with ovarian and endometrial pathologies in women with obesity. ${ }^{4}$ Furthermore, increased insulin resistance ${ }^{5}$ increased levels of leptin, ${ }^{6}$ hyperandrogenemia, ${ }^{7}$ and hypothalamic-pituitary-gonadal (HPG) axis dysregulation ${ }^{8}$ are considered to be responsible for the negative effects of obesity on reproductive health. These mechanisms can similarly result in impaired sexual functions, and there is a limited amount of information concerning the effects of obesity on female sexual function. ${ }^{9}$

Sexual dysfunction is a multifaceted and multidimensional condition that is related to biological, psychological, and personal factors, ${ }^{10}$ and obesity is associated with all of these factors. ${ }^{11}$ However, those who are affected by it rarely seek professional help, and it may cause serious problems for the affected individual and her partner. ${ }^{11}$ Psychological problems such as depression and anxiety, ${ }^{12}$ changes in sex hormones, ${ }^{13}$ and adipokines, ${ }^{14}$ which may be associated with obesity, were reported to have negative impacts on sexual functions. There are also various reports stating that female infertility has negative effects on sexual satisfaction ${ }^{15}$ and that fertility anxiety may affect sexual functions as an independent factor. ${ }^{16}$

The present study is aimed to investigate the sexual function problems in women obesity with infertility.

\section{METHODS}

A total of 600 women presenting to our gynecology clinic between January 1 and December 31, 2019 were evaluated. The inclusion criterion was being aged 20-45 years, within the reproductive period. The exclusion criteria were as follows: women who did not have sexual intercourse within the last one month, cases where the woman or her husband needed hospitalization for treatment, cases where women have not had their husbands at the same address within the last month, cases where woman or her husband had a medical condition that prevented sexual intercourse, use of alcohol and illegal drugs, use of psychiatric medication, presence of systemic diseases that render physical activity difficult/impossible, presence of genital anatomic anomalies, presence of pathologies that lead to masses in genital and pelvic organs, presence of genitourinary infections, and a diagnosis of endometriosis. Body mass indexes (BMI) were calculated, and those with a BMI of $18.5-24.9 \mathrm{~kg} / \mathrm{m}^{2}$ were considered as normal-weighed participants and those with a BMI of [?]30 $\mathrm{kg} / \mathrm{m}^{2}$ as obese participants. The cases where women had sexual intercourse regularly for 12 months and could not conceive a child despite not using a contraceptive method were considered as cases of infertility. 110 women were excluded from the study because they did not meet the inclusion criteria, and 40 women were excluded because they did not fully answer the questionnare questions. Finally, 150 women obesity without infertility, 150 women obesity with infertility, and 150 women normal-weighed without infertility who met the inclusion criteria were included in the study. 150 women normal-weighed without infertility consisted the control groups.

All of the participants were administered a sociodemographic data form to evaluate their sociodemographic data such as age, educational background, and marital status. Female Sexual Function Index (FSFI) and Beck Depression Inventory (BDI) were applied by the investigator. 


\subsection{Female sexual function index}

Developed by Rosen et al, ${ }^{17}$ FSFI was intended as a multidimensional scale consisting of 19 items to assess female sexual function. This scale assesses the sexual problems or function in the last 4 weeks. The scale composes of six subdimensions, which are desire, arousal, lubrication, orgasm, satisfaction, and pain. Each item has a score between 0 and 5. Its validity and reliability study for Turkish was conducted by Aygin and Aslan. ${ }^{18}$

\subsection{Beck depression inventory}

Developed by Beck et al, ${ }^{19}$ BDI measures the physical, emotional, cognitive, and motivational indicators observed in depression. The scale is intended to determine the degrees of depression indicators in an objective manner. There are four options under each of the 21 items, and each item is given a score between 0 and 3 . The total score varies between 0 and 63 . The cutoff score of the scale is 17 . Its validity and reliability study for Turkish was conducted by Hisli. ${ }^{20}$

\subsection{Statistical analysis}

Data collected for the study was uploaded to a computer and analyzed using "SPSS (Statistical Package for Social Sciences) for Windows 21.0 (SPSS Inc., Chicago, IL, USA)". Descriptive statistics were presented as mean + - standard deviation. Analytical methods (Kolmogorov-Smirnov/Shapiro-Wilk tests) were used to assess whether the variables had a normal distribution. Kruskal-Wallis test was used as the statistical method in cases of statistical significance between two independent groups for the variables that were found to be non-normally distributed. For the normally distributed variables, one-way analysis of variance (ANOVA) was used as the statistical method. Tukey test was used for post-hoc paired comparisons to determine the source of the difference in cases of statistical significance among three independent groups. The level of statistical significance was assumed as $P<0.05$.

\subsection{Ethics statement}

The present study protocol was reviewed and approved by the Ethics Committee of Alaaddin Keykubat University (approval no. 10354421) Informed consent was submitted by all subjects when they were enrolled.

\section{RESULTS}

The study included 150 women obesity without infertility, 150 women obesity with infertility and 150 women normal-weighed without infertility as a control group. No significant difference was noted among the groups in terms of age, educational background, and marital status. One-way ANOVA test, conducted to compare the FSFI scores of the three groups, revealed statistically significant differences. The post-hoc analysis also revealed differences between the groups of obesity without infertility and group of obesity with infertility $(P$ $=0.001)$, and the group of control and group of obesity with infertility $(P=0.001)$. The comparison of the groups' sociodemographic data and BMIs is presented in Table 1.

When the FSFI subscores were examined, the scores were observed to be significantly lower in the group of obesity with infertility than in the group of obesity without infertility and control group in terms of desire, arousal, lubrication, orgasm, satisfaction and pain. The comparison between FSFI subscores of the group of obesity without infertility, group of obesity with infertility and control group is presented in Table 2 .

It was determined that orgasm, satisfaction and pain sub-scores were negatively correlated with BMI in the group of obesity without infertility; orgasm, pain, desire, arousal, lubricity and satisfaction sub-scores were negatively correlated with BMI in the group of obesity with infertility. Correlation analyzes are shown in Table 3.

\section{DISCUSSION}

This study shows that women obesity with infertility have lower sexual function scores, and BMI has a negative effect on sexual health. 
Female sexuality plays an essential role in personal development, quality of life, and interpersonal relations in marriages. ${ }^{21}$ The present study is a cross-sectional one that is focused on the effects of obesity and infertility on sexual dysfunction and that investigates the sexual functions in obesity, obesity with infertility, and control groups. It is intended to shed light on the effects of obesity and infertility on female sexual function, about which there is a limited volume of information.

When the FSFI scores were compared, it was observed that the obesity without infertility group reported lower sexual function scores than the control group and also that BMI was negatively correlated with sexual functions in the group of obesity without infertility and group of obesity with infertility. Sexual dysfunctions are frequently reported in cases of obesity-associated diabetes and cardiovascular and mental diseases. ${ }^{22}$ However, the effects of obesityon female sexual dysfunction are still controversial in the literature. Esposito et $\mathrm{al}^{23}$ compared 52 women with obesity with normal weight controls, and reported that all of the FSFI subscores were lower in the obesity group and that BMI was strongly correlated with sexual dysfunction scores. In their study that included 45 women with obesity, Yaylali et al ${ }^{13}$ reported that $86 \%$ of the women with obesity defined sexual dysfunction, and that the subscores of orgasm and satisfaction were negatively correlated with BMI at a moderate level. Kadığlu et $\mathrm{al}^{24}$ found sexual dysfunction in $50 \%$ and $41 \%$ of the cases in the obesity group and in the control group, respectively, thereby concluding that obesity is not a strong factor by itself for sexual dysfunction. Similarly, Erbil et $\mathrm{al}^{25}$ also reported that BMI and sexual dysfunction are not correlated and that negative body image can be predictive of sexual functions. These differences might have been caused by the different cultures where the studies were conducted and differences in samples and measuring tools. Sexual dysfunction is significantly higher in the eastern cultures, where there is a sexual taboo and sexual education is not integrated into the education given at schools. ${ }^{26}$ Similarly, sexual dysfunction is considered as an important health problem for women with obesity.

When the FSFI subscores were examined, the scores were observed to be significantly lower in the group of obesity with infertility than in the group of obesity without infertility and control groups in terms of desire, arousal, lubrication, orgasm, satisfaction, and pain. Obesity poses a risk for most of the underlying etiologies for infertility, and current evidences describe obesity alone as a risk factor for infertility. ${ }^{27}$ Infertility alone may cause psychiatric problems just, ${ }^{28}$ and it was also reported that patients with obesity and menstruation problems have 8.1 times higher risk of clinic depression than healthy controls. ${ }^{29}$ It is known that sexual dysfunction, particularly arousal problems, is common in women with infertility, ${ }^{30}$ and women who present for invitro fertilization were reported to have lower self-confidence scores than controls. ${ }^{27}$ In another study, infertile women who want to conceive a child and those who voluntarily underwent sterilization were reported to have similar sexual functions; however, the group of infertile women experienced higher levels of stress. ${ }^{31}$ In a study that examined a group of patients with polycystic ovaries, where in obesity and infertility are frequently comorbid, it was reported that obesity and infertility had adverse effects on sexual life and that obesity had a greater impact. ${ }^{32}$ The results from the present study indicate that infertility and obesity are in a two-way interaction and that both conditions cause sexual dysfunction.

The limitations of the study may be the fact that patients' sex hormones were not studied. There is a complex relationship between sex hormones and sexual functions, and women with obesity were observed to have statistically increased levels of sex hormones and sexual functions following bariatric surgery. ${ }^{33}$

It has been found in our study that sexual dysfunction is higher in women with obesity and infertility and that this dysfunction is correlated with BMI. It is therefore important that healthcare professionals adopt a holistic approach that incorporates sexual health consultancy to improve the treatment and quality of life in women with obesity and infertility.

\section{REFERENCES}

1. Seidell JC, Halberstadt J. The global burden of obesity and the challenges of prevention. Ann Nutr Metab $2015 ; 66: 7-12$.

2. Gallagher EJ, LeRoith D. Obesity and diabetes: the increased risk of cancer and cancer-related mortality. Physiol Rev 2015;95:727-748. 
3. Lashen H, Fear K, Sturdee D. Obesity is associated with increased risk of first trimester and recurrent miscarriage: matched case-control study. Hum Reprod 2004;19:1644-1646.

4. Vahratian A. Prevalence of overweight and obesity among women of childbearing age: results from the 2002 National Survey of Family Growth. Matern Child Health J 2009;13:268.

5. Al-Jefout M, Alnawaiseh N, Al-Qtaitat A. Insulin resistance and obesity among infertile women with different polycystic ovary syndrome phenotypes. Sci Rep 2017;7:1-9.

6. Kumari P, Jaiswar S, Shankhwar P, et al. Leptin as a predictive marker in unexplained infertility in north indian population. J Clin Diagn Res 2017;11:QC28-31.

7. Banu LM, Begum D, Rahman SA, Mollah FH, Ferdousi S, Habibullah M. Correlation of hyperinsulinemia with hyperandrogenemia in primary infertile women with polycystic ovary syndrome. Mymensingh Med J $2015 ; 24: 127-132$.

8. Tsatsanis C, Dermitzaki E, Avgoustinaki P, Malliaraki N, Mytaras V, Margioris AN. The impact of adipose tissue-derived factors on the hypothalamic-pituitary-gonadal (HPG) axis. Hormones 2015;14:549-562.

9. Larsen SH, Wagner G, Heitmann BL. Sexual function and obesity. Int J Obes 2007;31:1189-1198.

10. Steinke E, Palm Johansen P, Fridlund B, Broström A. Determinants of sexual dysfunction and interventions for patients with obstructive sleep apnoea: a systematic review. Int J Clin Pract 2016;70:5-19.

11. Kolotkin RL, Binks M, Crosby RD, Østbye T, Gress RE, Adams TD. Obesity and sexual quality of life. Obesity 2006;14:472-479.

12. Kendler KS, Kessler RC, Walters EE, et al. Stressful life events, genetic liability, and onset of an episode of major depression in women. Focus 2010;8:459-470.

13. Yaylali G, Tekekoglu S, Akin F. Sexual dysfunction in obese and overweight women. Int J Impot Res 2010;22:220-226.

14. Plaisance EP, Grandjean PW, Judd RL, Jones KW, Taylor JK. The influence of sex, body composition, and nonesterified fatty acids on serum adipokine concentrations. Metabolism 2009;58:1557-1563.

15. Kaya Y, Kaya C, Tahta T, Kartal T, Tokgöz VY. Examination of the effect of COVID-19 on sexual dysfunction in women. Int J Clin Pract 2021;75:e13923.

16. Pakpour AH, Yekaninejad MS, Zeidi IM, Burri A. Prevalence and risk factors of the female sexual dysfunction in a sample of infertile Iranian women. Arch Gynecol Obstet 2012;286:1589-1596.

17. Rosen R, Brown C, Heiman J, et al. The Female Sexual Function Index (FSFI): a multidimensional self-report instrument for the assessment of female sexual function. J Sex Marital Ther 2000;26:191-208.

18. Aygin D, Aslan FE. The Turkish adaptation of the female sexual function index. J Med Sci 2005;25:393399.

19. Beck AT, Ward CH, Mendelson M, Mock J, Erbaugh J. An inventory for measuring depression. Arch Gen Psychiatry 1961;4:561-571.

20. Hisli N.A. Reliability and validity study of Beck Depression Inventory in a university student sample. J Turk Psychol 1989;7:3-13.

21. Jarząbek-Bielecka G, Sowińska-Przepiera E, Pawlaczyk M. Aging and sexual activity: gynecological, sexological and psychological aspects. Przeglad Menopauzalny 2012;16:487-489.

22. Alidu H, Owiredu WKBA, Amidu N, et al. Hypertension and obesity comorbidities increases coronary risk, affects domains of sexual function and sexual quality of life. Int J Impot Res 2018;30:8-13. 
23. Esposito K, Ciotola M, Giugliano F, et al. Association of body weight with sexual function in women. Int J Impot Res 2007;19:353-357.

24. Kadioglu P, Yetkin DO, Sanli O, Yalin AS, Onem K, Kadıoglu A. Obesity might not be a risk factor for female sexual dysfunction. BJU Int 2010;106:1357-1361.

25. Erbil N. The relationships between sexual function, body image, and body mass index among women. Sex Disabil 2013;31:63-70.

26. Erenel AŞ, Kılınc FN. Does Obesity Increase Sexual Dysfunction in Women? Sex Disabil 2013;31:53-62.

27. Rittenberg V, Seshadri S, Sunkara SK, Sobaleva S, Oteng-Ntim E, El-Toukhy T. Effect of body mass index on IVF treatment outcome: an updated systematic review and meta-analysis. Reprod Biomed Online 2011;23:421-439.

28. Biringer E, Howard LM, Kessler U, Stewart R, Mykletun A. Is infertility really associated with higher levels of mental distress in the female population? Results from the North-Trøndelag Health Study and the Medical Birth Registry of Norway. J Psychosom Obstet Gynaecol 2015;36:38-45.

29. Cinar N, Kizilarslanoglu MC, Harmanci A, et al. Depression, anxiety and cardiometabolic risk in polycystic ovary syndrome. Hum Reprod 2011;26:3339-3345.

30. Jain K, Radhakrishnan G, Agrawal P. Infertility and psychosexual disorders: relationship in infertile couples. Indian J Med Sci 2000;54:1-7.

31. Monga M, Alexandrescu B, Katz SE, Stein M, Ganiats T. Impact of infertility on quality of life, marital adjustment, and sexual function. Urology 2004;63:126-130.

32. Barnard L, Ferriday D, Guenther N, Strauss B, Balen AH, Dye L. Quality of life and psychological well being in polycystic ovary syndrome. Hum Reprod 2007;22:2279-2286.

33. Sarwer DB, Spitzer JC, Wadden TA, et al. Changes in sexual functioning and sex hormone levels in women following bariatric surgery. JAMA Surg 2014;149:26-33.

TABLE 1 Comparison of sociodemographic data of groups

\begin{tabular}{|c|c|c|c|c|c|}
\hline $\begin{array}{l}\text { Study } \\
\text { Parameter }\end{array}$ & $\begin{array}{l}\text { Group of } \\
\text { obesity } \\
\text { without } \\
\text { infertility (n: } \\
\text { 150) }\end{array}$ & $\begin{array}{l}\text { Group of } \\
\text { obesity with } \\
\text { infertility (n: } \\
150)\end{array}$ & $\begin{array}{l}\text { Control group } \\
(\mathrm{n}: 150)\end{array}$ & Test statistics & $P$ value \\
\hline Age & $\begin{array}{l}31.3 \pm 3.9 \\
(29.2-33.4)\end{array}$ & $\begin{array}{l}31.2 \pm 3.8 \\
(29.3-33.1)\end{array}$ & $\begin{array}{l}31.1 \pm 4.5 \\
(30.4-34.0)\end{array}$ & KW: 0.38 & 0.827 \\
\hline $\begin{array}{l}\text { Education } \\
\text { Level (years) }\end{array}$ & $11.6 \pm 3.2$ & $11.8 \pm 4.1$ & $12.1 \pm 4.4$ & $F: 3.16$ & 0.432 \\
\hline $\begin{array}{l}\text { Marital } \\
\text { Status } \\
\text { (married) }\end{array}$ & $93.4 \%$ & $100.0 \%$ & $96.7 \%$ & $\chi 2: 3.730$ & 0.156 \\
\hline $\begin{array}{l}\text { Body Mass } \\
\text { Index }\end{array}$ & $\begin{array}{l}34.1 \pm 2.0 \\
(32.5-36.1)\end{array}$ & $\begin{array}{l}34.6 \pm 2.1 \\
(31.9-36.8)\end{array}$ & $\begin{array}{l}22.4 \pm 1.7 \\
(21.7-23.4)\end{array}$ & KW:300.71 & 0.001 \\
\hline $\begin{array}{l}\text { FSFI total } \\
\text { Scores }\end{array}$ & $21.0 \pm 3.7$ & $19.6 \pm 3.6$ & $27.1 \pm 4.3$ & $\mathrm{~F}: 159.84$ & $0.001^{\mathrm{a}}$ \\
\hline
\end{tabular}

Note: F: One-way ANOVA test, $\chi 2$ :Chi-Square test, KW: Kruskal-Wallis, FSFI: Female Sexual Function Index 
a There was a difference between Post-hoc Tukey test, group of obesity without infertility and group of obesity with infertility $(P=0.003)$, control group and group of obesity without infertility $(P=0.001)$, control group and group of obesity with infertility $(P=0.001)$.

TABLE 2 Comparison of FSFI sub-scores of groups

\begin{tabular}{|c|c|c|c|c|c|c|c|}
\hline $\begin{array}{l}\text { Study } \\
\text { Parameter }\end{array}$ & $\begin{array}{l}\text { Study } \\
\text { Parameter }\end{array}$ & $\begin{array}{l}\text { Study } \\
\text { Parameter }\end{array}$ & $\begin{array}{l}\text { Group of } \\
\text { obesity } \\
\text { without } \\
\text { infertility } \\
(\mathrm{n}: 150)\end{array}$ & $\begin{array}{l}\text { Group of } \\
\text { obesity } \\
\text { with } \\
\text { infertility } \\
(\mathrm{n}: 150)\end{array}$ & $\begin{array}{l}\text { Control } \\
\text { group (n: } \\
150)\end{array}$ & KW & $P$ value \\
\hline \multirow[t]{12}{*}{$\begin{array}{l}\text { FSFI } \\
\text { subscales }\end{array}$} & Desire & $\begin{array}{l}\text { Mean } \pm \\
\text { SD }\end{array}$ & $3.89 \pm 0.78$ & $3.46 \pm 0.71$ & $4.39 \pm 0.75$ & 2.489 & 0.001 \\
\hline & & Mean rank & 222.02 & 163.46 & 291.02 & & \\
\hline & Arousal & $\begin{array}{l}\text { Mean } \pm \\
\text { SD }\end{array}$ & $2.59 \pm 0.51$ & $2.51 \pm 0.50$ & $3.54 \pm 0.56$ & 1.372 & 0.001 \\
\hline & & Mean rank & 164.03 & 176.52 & 335.95 & & \\
\hline & Lubrication & $\begin{array}{l}\text { Mean } \pm \\
\text { SD }\end{array}$ & $3.61 \pm 0.60$ & $3.18 \pm 0.74$ & $4.55 \pm 0.68$ & 2.288 & 0.001 \\
\hline & & Mean rank & 199.12 & 149.86 & 327.52 & & \\
\hline & Orgasm & $\begin{array}{l}\text { Mean } \pm \\
\text { SD }\end{array}$ & $3.36 \pm 0.61$ & $2.97 \pm 0.65$ & $4.58 \pm 0.67$ & 2.397 & 0.001 \\
\hline & & Mean rank & 142.14 & 193.30 & 341.06 & & \\
\hline & Satisfaction & $\begin{array}{l}\text { Mean } \pm \\
\text { SD }\end{array}$ & $3.37 \pm 0.59$ & $3.04 \pm 0.60$ & $4.81 \pm 0.66$ & 2.455 & 0.001 \\
\hline & & Mean rank & 180.71 & 140.17 & 355.63 & & \\
\hline & Pain & $\begin{array}{l}\text { Mean } \pm \\
\text { SD }\end{array}$ & $4.21 \pm 0.58$ & $4.01 \pm 0.27$ & $5.21 \pm 059$ & 3.615 & 0.001 \\
\hline & & Mean rank & 187.29 & 164.33 & 324.86 & & \\
\hline
\end{tabular}

Note: KW: Kruskal-Wallis, FSFI: Female Sexual Function Index

TABLE 3 FSFI and BMI correlation analysis between group of obesity with infertility and group of obesity without infertility

\begin{tabular}{|c|c|c|c|c|c|}
\hline $\begin{array}{l}\text { Study } \\
\text { Parameter }\end{array}$ & $\begin{array}{l}\text { Study } \\
\text { Parameter }\end{array}$ & $\begin{array}{l}\text { Group of } \\
\text { Obesity with } \\
\text { infertility BMI } \\
(\mathrm{n}: 150)\end{array}$ & $\begin{array}{l}\text { Group of } \\
\text { Obesity with } \\
\text { infertility BMI } \\
(\mathrm{n}: 150)\end{array}$ & $\begin{array}{l}\text { Group of } \\
\text { Obesity } \\
\text { without } \\
\text { Infertility } \\
\text { BMI (n: 150) }\end{array}$ & $\begin{array}{l}\text { Group of } \\
\text { Obesity } \\
\text { without } \\
\text { İnfertility } \\
\text { BMI (n: 150) }\end{array}$ \\
\hline & & $\begin{array}{l}\text { Spearman } \\
\text { rho }\end{array}$ & $P$ value & $\begin{array}{l}\text { Spearman } \\
\text { rho }\end{array}$ & $P$ value \\
\hline \multirow{7}{*}{$\begin{array}{l}\text { FSFI total } \\
\text { FSFI } \\
\text { sub-scores }\end{array}$} & FSFI total & -0.535 & 0.001 & -0.198 & 0.015 \\
\hline & Desire & -0.313 & 0.001 & -0.037 & 0.649 \\
\hline & Arousal & -0.316 & 0.001 & -0.016 & 0.337 \\
\hline & Lubrication & -0.326 & 0.001 & -0.159 & 0.052 \\
\hline & Orgasm & -0.477 & 0.001 & -0.210 & 0.01 \\
\hline & Satisfaction & -0.398 & 0.001 & -0.290 & 0.001 \\
\hline & Pain & -0.380 & 0.001 & -0.287 & 0.001 \\
\hline
\end{tabular}


Note: FSFI: Female Sexual Function Index, BMI: Body Mass Index 